\title{
INFLUENCE OF ROV UMBILICAL ON POWER QUALITY WHEN SUPPLYING ELECTRICAL LOADS
}

\author{
P. Snary*, C.M. Bingham, D.A. Stone \\ Department of Electronic and Electrical Engineering \\ University of Sheffield, Mappin Street, Sheffield, S1 3JD, UK \\ Tel. +44 (0) 1142225849 \\ *Corresponding author: e-mail: p.snary@sheffield.ac.uk
}

\section{Acknowledgements}

The authors would like to acknowledge the support of the EPSRC UK for providing funds to carry out the research presented in this paper.

Keywords: Matrix Converters Marine Power transmission

\begin{abstract}
The paper investigates the effects of a $3 \mathrm{~km}$ electrical umbilical cable on power transmission for an "island" supply onboard an all/more electric 'work-class' Remote Operated Vehicle (ROV). It is shown how the chosen transmission voltage and frequency influence efficiency and the selection of power transmission components. A key feature of the paper is a discussion on the use of matrix converters for the propulsion thruster drive system; thereby allowing the input displacement factor to be varied to maintain maximum power transmission efficiency, independent of the thruster power factor. The natural impedance characteristics of the umbilical cable are also considered as means of reducing the input filter requirements for such converters.
\end{abstract}

\section{Introduction}

Several industrial sectors including those concerned with automotive, aerospace and marine systems are striving to replace hydraulically controlled actuation technologies by electrically based counterparts; the perceived advantages being reduced overall mass, increased reliability, increased efficiency and increased controllability [1]. Typically, for 'work-class' ROVs, at least 6 propulsion thruster units are necessary to achieve six-degrees-of-freedom positioning of the ROV and associated manipulators and other tooling and auxiliaries. Whilst the power density of the electrical servo machines is not as high as hydraulic-based counterparts, when considering the overall system including cable routing and support systems, electric actuation becomes a favoured solution.

The nominal operating depth of these ROVs is $3 \mathrm{~km}$ below sea level, where the ambient pressure is 300bar, thereby requiring electronic components and systems to be traditionally housed in heavily constructed lbar pressure chambers. However, the ambient temperature at such depths is approximately constant, at $4^{\circ} \mathrm{C}$, making it highly desirable to operate power electronic drive systems in thin walled enclosures to improve the thermal conductivity from the power devices to the "essentially infinite" heat sink provided by the surrounding seawater. Consequently, this requires all electrical components to function at increased ambient pressures.

Active and static experiments have been previously reported [2] that identify electrical components that remain operational when subject to pressures in excess of 300bar, and the various failure mechanisms of commonly used components and device packages, such as electrolytic capacitors which are shown to be extremely pressure sensitive. Consequently, alternative drive topologies to that of the industry standard Voltage Source Inverter (VSI) have been investigated, since VSIs typically require a large capacitance on the DC link to provide energy storage, and decoupling between the inverter and the supply. 
Matrix converters provide direct 3-phase conversion with the flexibility of output amplitude, output frequency and input displacement factor control. By virtue of providing direct ac-ac conversion, they exhibit increased power density and reliability compared with conventional VSIs \& CSIs due to the elimination of large energy storage components associated with the DC link - the only energy storage components required being associated with line input filters that are of significantly lower values (and size) than those found in link-based converters, and those used in the clamp protection circuitry that can be selected from a range of pressure tolerant devices [2,3]. Although it is not possible to eliminate the filter capacitors completely, the paper details the use of the power transmission cable impedance to reduce the size of the reactive components of the input filter, increasing the power density of the converter.

Here then, from models of the power transmission system, a review of power transmission voltage and frequency options are considered. Comparisons are then made between possible configurations of input filters for on-board matrix converter-based drive systems. It is shown that the use of such converter configurations, and the flexibility they provide to control input power factor, can ultimately improve overall power transmission efficiency.

\section{Transmission System}

A power transmission system typically employed on ROVs is shown in Fig. 1(a), which comprises of a hydraulic power pack, rated at $95 \mathrm{~kW}$ (in this case), powered by a direct-on-line start induction machine with a nominal power factor of 0.83 . The generator system consists of a ship-board, 3-phase generator supplying $120 \mathrm{KVA}, 440 \mathrm{Vline}, 60 \mathrm{~Hz}$; and a step-up transformer with a $3.3 \mathrm{kV}$ delta connected secondary winding. This, in-turn is connected to the $3 \mathrm{~km}$ umbilical used to transmit power to the ROV. In a conventional hydraulically powered $\mathrm{ROV}$, the $3.3 \mathrm{kV}$ is directly connected to an induction machine/pump combination to provide hydraulic pressure for the actuators and thrusters. However, for the case considered here, an all-electrical system, the high input voltage is transformed down, and distributed directly to the matrix converter drives, Fig. 1(b).

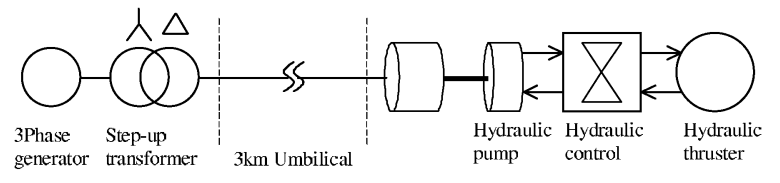

(a)

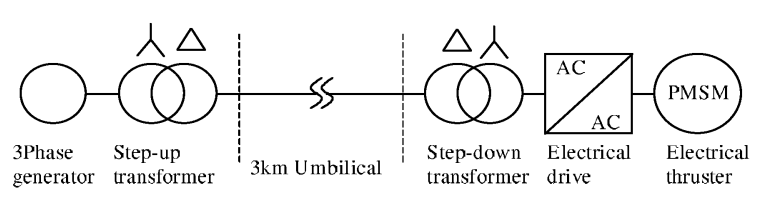

(b)

Fig. 1. Transmission Systems (a) Conventional hydraulic system (b) Electrical transmission configuration

\section{Transformer Model}

Models of the surface step-up and subsea step-down transformers have been developed, based on data from short- and open-circuit tests. For the proposed electrically-based system, a similar transformer as described above is employed for the sub-sea step down transformer. By monitoring the excitation currents when open-circuit tests are conducted, values for the magnetising inductance, $L_{m}(1)$ and the core loss represented by a resistance, $R_{c}(2)$, are obtained. The voltage drop as a result of the winding impedance is neglected during the test, since the supply current is small compared to the full load current ( $4 \%$ in this case).

$$
\begin{aligned}
L_{m} & =\frac{\sqrt{3} V_{o c}}{\omega I_{e x} \sin \left(\cos ^{-1} \frac{P_{o c}}{\sqrt{3} V_{o c} I_{e x}}\right)} \mathrm{H} \\
R_{c} & =\frac{3 V_{o c}^{2}}{P_{o c}} \Omega
\end{aligned}
$$


where $\omega$ is the angular frequency of the supply, $I_{e x}$ is the excitation current, $V_{o c}, P_{o c}$ is the open circuit voltage and power respectively.

To enable the winding impedance to be calculated, short circuit tests have also been performed to obtain the short circuit parameters current, $I_{s c}$, voltage, $V_{s c}$ and power, $P_{s c}$. The impedance of the short will be significantly less than the shunt admittance components, and are therefore neglected from the calculations. Winding resistance and leakage inductance, $R_{s c}$ and, $L_{s c}$ respectively, are subsequently calculated from (3),(4) as given below, and are referred to the low voltage winding through the turns ratio $a$, with the resulting model given in Fig. 2

$$
\begin{aligned}
& R_{s c}=\frac{P_{s c}}{3 I^{2} s c} \Omega \\
& L_{s c}=\frac{V_{s c} \sin \left(\cos -1 \frac{I_{s c} R_{s c}}{V_{s c}}\right)}{\omega I_{s c}} \mathrm{H}
\end{aligned}
$$

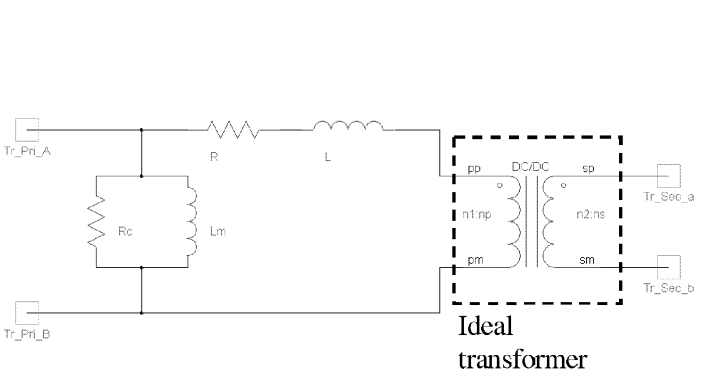

Components

$R_{c}($ core loss $)$

$L_{m}$ (magnetising inductance)

$R$ (winding resistance referred to low voltage winding)

$L$ (winding inductance referred to low voltage winding)
Value

$509.47 \Omega$

$410 \mathrm{mH}$

$21.6 \mathrm{~m} \Omega$

$310 \mu \mathrm{H}$

Fig. 2. Single phase of the transformer model and parameter values

\section{Transmission Line Model}

A typical 3-phase transmission line for ROVs consists of a $3 \mathrm{~km}$ of umbilical, each phase having 2 parallel conductors, see Fig. 3.

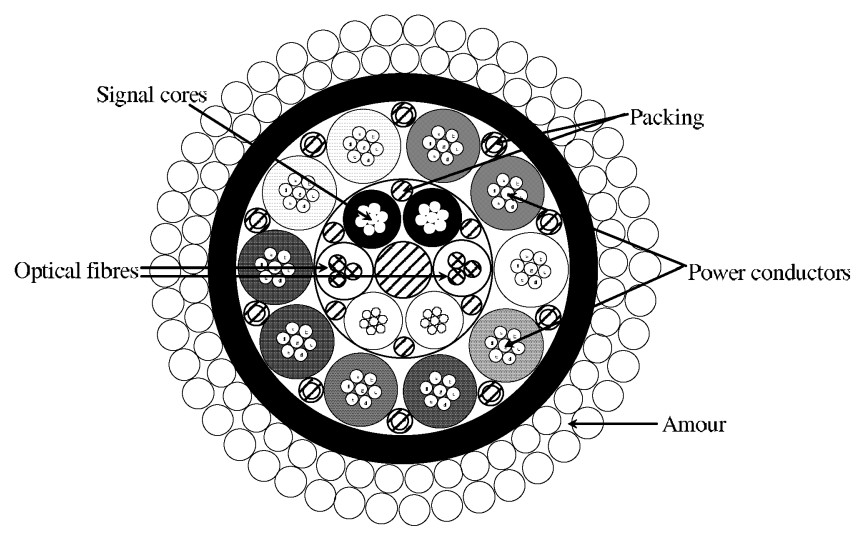

Fig. 3. Cross-section of umbilical cable

$\begin{array}{ll}\begin{array}{ll}\text { Power Conductor } \\ \text { Conductor strands }\end{array} & \begin{array}{l}10 \\ 7 \times 1.04 \mathrm{~mm} \text { dia. } \\ \text { copper } \\ \text { Polyethylene }\end{array} \\ \text { Insulation } & \begin{array}{l}1.1 \mathrm{~mm} \\ \text { Pnsulation thickness }\end{array} \\ \text { Outer jacket } & \begin{array}{l}\text { Polyethylene } \\ \text { Jacket thickness }\end{array} \\ \text { Jacket diameter } & 29.3 \mathrm{~mm} \\ \text { Armour } & \text { Galvanised steel } \\ \text { Inner layer } & 2.2 \mathrm{~mm} \text { dia } \\ \text { Outer layer } & 2.4 \mathrm{~mm}\end{array}$

$2.4 \mathrm{~mm}$

In comparison to grid transmission lines, $3 \mathrm{~km}$ lengths are considered relatively short, and would normally allow the use of short-line lumped parameter models at low transmission frequencies (eg. $60 \mathrm{~Hz}$ ). However, whilst a short-line model can be accurately employed for investigating overhead 
power lines of up to $80 \mathrm{~km}$ in length (since the effect of shunt capacitance, $C$, and conductance, $G$, are negligible), the close proximity of the conductors within the umbilical considered here has a pronounced effect on shunt capacitance and conductance especially at frequency beyond $60 \mathrm{~Hz}$. Here then, a medium-line model, Fig. 4, is therefore adopted. Component parameters of resistance, inductance and capacitance given in Fig. 4 and are calculated from standard power transmission cable equations[4] and verified through experimental procedures, which also allowed a value for conductance to be derived.

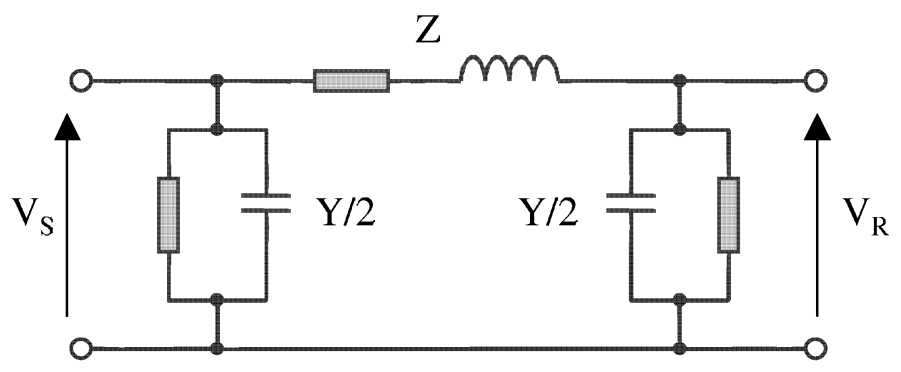

$\begin{array}{ll}\text { Parameter } & \text { Values } \\ \text { Resistance } & 8.57 \Omega \\ \text { Inductance } & 0.954 \mathrm{mH} \\ \text { Capacitance } & 0.42 \mu \mathrm{F} \\ \text { Conductance } & 227 \mathrm{k} \Omega\end{array}$

Fig. 4. Per-phase transmission line model of umbilical and single conductor parameter values for $3000 \mathrm{~m}$ of umbilical

\section{Transmission Voltage}

For a given current density along the umbilical cable, Fig. 5 shows that increased transmission efficiency can be achieved by increasing transmission voltage, since the cable copper loss becomes a lower percentage of the overall power delivered to the load.

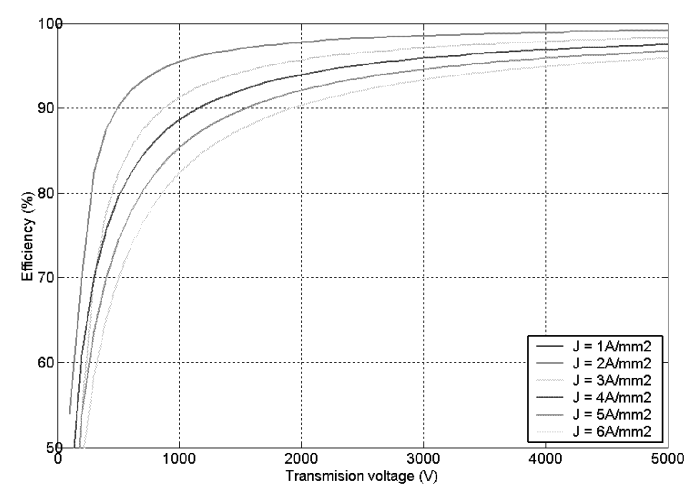

Fig. 5. The variation of transmission efficiency due to changes in transmission voltage for various current densities

Whilst reducing current density improves efficiency, it also requires greater conductor diameters, thereby resulting in higher umbilical mass and increased umbilical hydrodynamic drag (necessitating greater power to be transferred to the ROV) and increased lifting capacity of the launch and recovery equipment. Moreover, heat dissipation in conductors within the umbilical, which remain wrapped around the surface winch whilst the ROV is operational, place a sustainable upper limit on the current density of $2 \mathrm{~A} / \mathrm{mm}^{2}$. In this case, it can be seen that a transmission voltage of $3.3 \mathrm{kV}$ provides an expected transmission efficiency in excess of $95 \%$ (from Fig. 5).

\section{Transmission Frequency}

By increasing the transmission frequency, a significant reduction in the volume-envelope of wirewound and other reactive components can be achieved. Such a reduction is of particular importance when considering the inclusion of a sub-sea step-down transformer. As a first-order approximation, the volume of a power transformer decreases in inverse proportion to operating frequency, with a corresponding reduction in mass. However, this does consider increases in iron loss and the possible requirement for increased parallel winding as a result of reduced skin depth. Practically a reduction in 
transformer mass by $\approx 66 \%$ can be expected through increasing operating frequency from $60 \mathrm{~Hz}$ to $400 \mathrm{~Hz}$.

The 'AC-resistance' resulting from skin effect in the umbilical must be considered as the transmission frequency is increased, since it ultimately reduces transmission efficiency. When conductors are subject to a time-varying current, eddy currents are induced in the conductors that oppose the net current flow. Electromagnetic fields induced within the conductor result in an exponentially decaying current density toward the centre of the conductor, effectively increasing the resistance, as described by $(5)$ where the skin depth, $\delta$ is given by $(6)[5,6]$. Nevertheless, with reference to Fig. 6 , it can be seen that at normal transmission frequencies $(<1 \mathrm{kHz})$ the bulk DC-resistance remains dominant, given by (7), and the AC-resistance has a negligible contribution.

$$
\begin{aligned}
& R_{A C}=\operatorname{real}\left(\frac{\frac{(1+j)}{\delta} \text { Besselj }\left(0, \frac{(1+j)}{\delta} d / 2\right)}{\pi d \sigma \text { Besselj }\left(1, \frac{(1+j)}{\delta} d / 2\right)}\right) \Omega \\
& \delta=\frac{2}{\sqrt{\omega \mu \sigma}} \mathrm{mm} \\
& R_{d c}=\frac{\rho l}{A} \Omega
\end{aligned}
$$

where, $\rho$ is the resistivity of copper, $l$ is the length of conductor and $A$ is the cross sectional area.

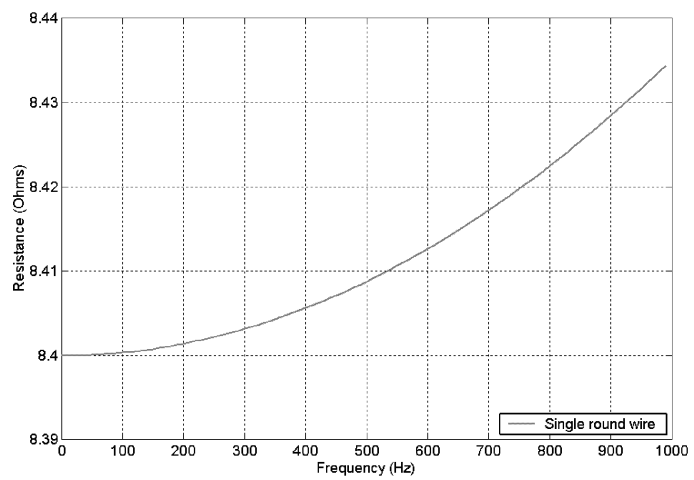

Fig. 6. Transmission frequency vs resistance

Here then, increasing the transmission frequency, up to $1 \mathrm{kHz}$, has negligible effect on efficiency but can result in a significant reduction in the size of the power transformer.

Complete knowledge of the load connected to the transmission system, and its associated power factor, is essential for calculating the efficiency of power transfer from the surface generator to the sub-sea ROV. At frequencies up to $400 \mathrm{~Hz}$, a load with unity power factor provides the most efficient power transfer, as can be seen from Fig. 7. However, Fig. 7 also shows that with increased transmission frequency, maximum power transfer occurs when the load develops a small lagging power factor. The ability to control the load input displacement factor, as provided by matrix converters, thereby facilitates maximum transmission efficiency for a particular supply frequency and voltage. 


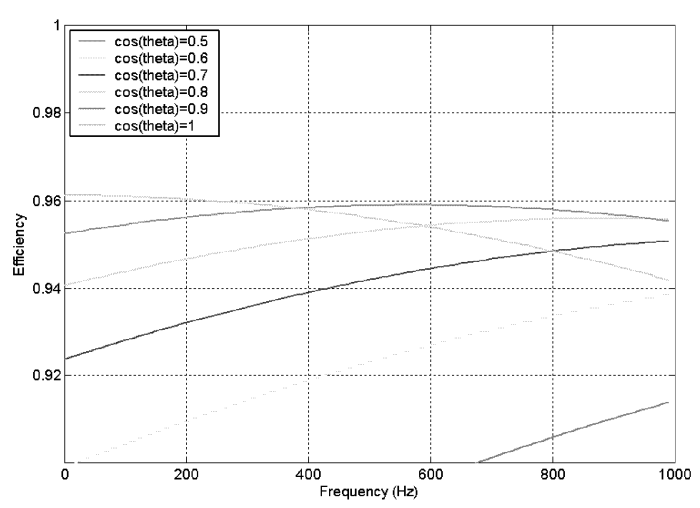

Fig. 7. Transmission frequency vs efficiency for loads of various power factor system components. Study conducted using $3000 \mathrm{~m}$ of umbilical cable

\section{Matrix Converter Drive System Solutions}

The common matrix converter topology, Fig. 8, consists of 9 bidirectional switches that provides inherent 4 quadrant operation, arranged such that any input phase can be connected to any output phase, allowing direct ac-ac conversion with minimal energy storage. The need for passive energy storage components in the power stage is therefore reduced to those required for the input filter to minimise the propagation of input switching harmonics, and a small clamp circuit to provided protection against high voltages under emergency shut down and power failure conditions.

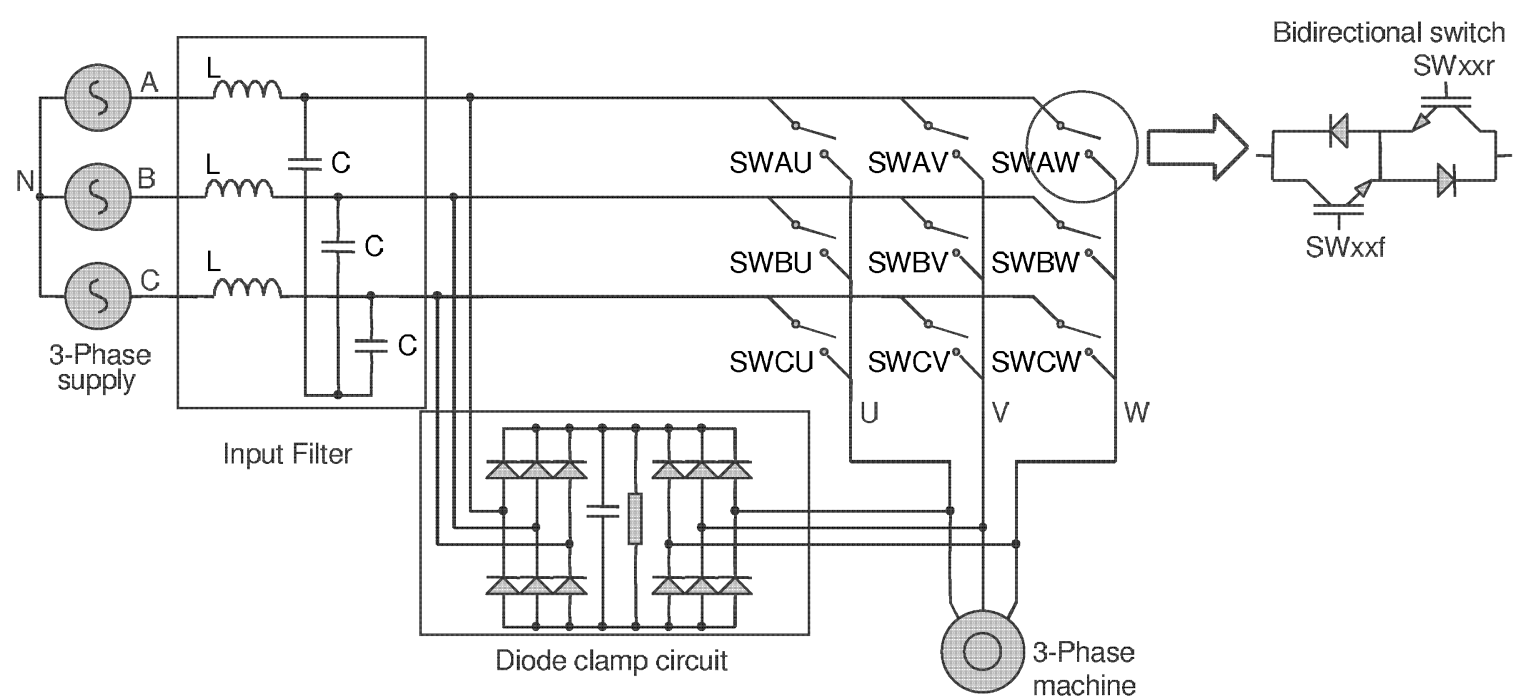

Fig. 8. Configuration of a typical 3phase-3phase matrix converter showing in-line filter components and bidirectional switch configuration

The conventional input filter configuration consists of an inductor with a shunt capacitance, as illustrated in Fig. 8, thereby forming a standard $2^{\text {nd }}$ order low pass filter. However, since the umbilical cable possesses significant inductance, this can also contribute to the overall filter inductance requirements. Consequently consideration is now given to the passive component requirements for the input filters to matrix converters, which are employed to reduce the amplitude of high frequency current harmonics injected back into the supply, along with the cascaded arrangement of the input filter and transmission system.

An input filter is a pre-requisite for attenuating input current harmonics clustered about the switching frequency and integer multiples of it. Although the high frequency harmonics should be attenuated, the filter should not influence the requirements for connection to a matrix converter-thereby presenting a voltage source to the converter at low frequency. Furthermore, to maintain high efficiency the filter should be designed for reduced loss and minimum impact on displacement factor 
(for reasons discussed previously). Several circuit arrangements to perform this task have been previously identified $[7,8,9,10]$, the most common being the second-order series-L/shunt-C arrangement, Fig. 8 which can include a damping resistor, Fig. 9(a). This, along with other variants such as, LLC Fig. 9(b), the LCC filter, Fig. 9(c) and the cascade arrangement, Fig. 9(d) are therefore considered.

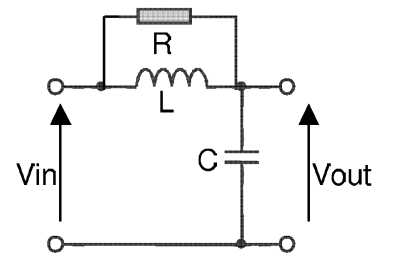

(a)

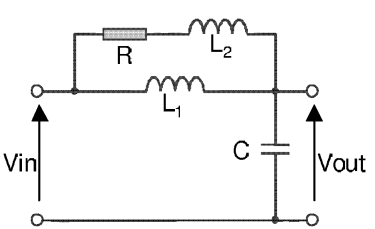

(b)

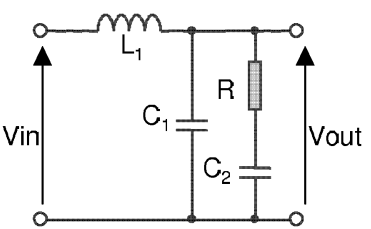

(c)

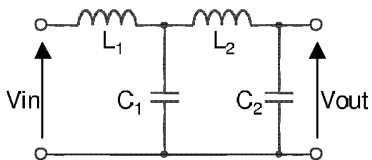

(d)

Fig. 9. Per-phase low pass filter configurations (a) Damped RLC filter (b) LLC filter (c) LCC filter (d) cascade LC low-pass filter

An appraisal of the relative attributes of the presented filters is given in terms of roll-off rates beyond the corner frequency, Fig. 10 and efficiency, Fig. 11. Component values are chosen to create a corner frequency at $2 \mathrm{kHz}$, thereby providing a sufficient transition region between the input and output frequencies such that they are not unduly attenuated, whilst providing attenuation at the converter PWM switching frequency. For the design of both the damped LC Fig. 9(a) the LLC Fig. 9(b) and LCC Fig. 9(c) filters, the damping factor are chosen to be 0.1 so to maintain a high roll off in the frequency region of the PWM. Values of $C_{2}$ for the LCC filter is chosen to be $4 C_{l}$ where as $L_{2}=4 L_{1}$.

From the results, it can be seen both LLC and LCC filters have a marginal increase in efficiency when compared with the standard second order filter and all impart superior efficiency compared to their first-order counterparts, since they eliminate the series resistor. Although the LLC and LCC filters have a marginal increase in efficiency over the standard second order filter, the reduced component count and reduced volume of the latter makes it a preferred solution.

For this application, the key region in the frequency response is the first decade following the corner frequency, since the switching frequency is within this region. It is therefore important to achieve the maximum possible attenuation up to the first set of harmonics. From Fig. 10, the attenuation characteristics of the second-order filter during the first decade beyond the corner frequency, is equal to that of more complex filters. Consequently, the second order filter is again chosen in preference. A design procedure is therefore proposed in the next section.
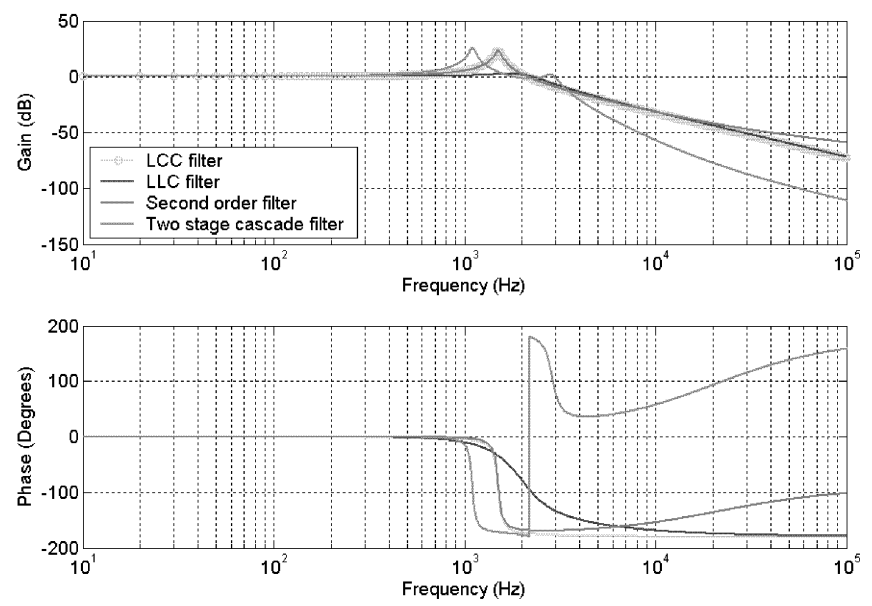

Fig. 10. Comparison of the filter frequency characteristics 


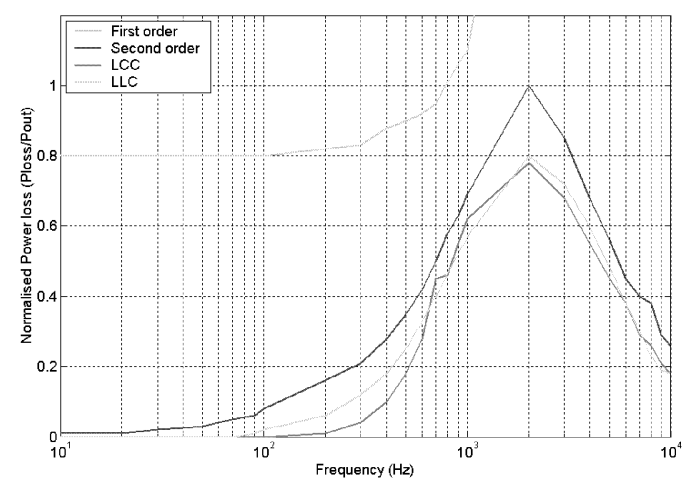

Fig. 11. Power loss for the candidate filter networks

To maintain the optimal displacement factor over the full operating range, a maximum limit on the value of capacitance for a given power rating of the converter exists [11]. For stability, it is beneficial to have a low impedance source presented to the converter, requiring a high capacitor value and low inductor value. Consequently, the choice of maximum capacitance is according to [12] to reduce the inductor size, which is necessary to obtain the required corner frequency. This also minimises the voltage drop across the series $L$, reducing the voltage ripple at the terminals of the converter and thereby improving stability. The effect of the output power on the input displacement factor is shown in Fig. 12, where it can be seen that a filter load power above $300 \mathrm{~W}$ yields an input displacement factor of $>0.8$.

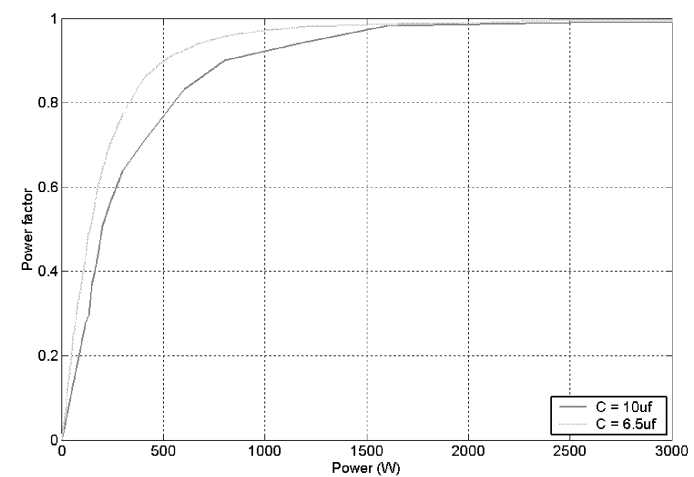

Fig. 12. Variation of input displacement factor with filter load power

\section{Complete System}

Subsequent to design of the matrix converter and ancillary components, the power distortion introduced by using the converter on an island supply, can be investigated. The complete system has previously been shown in Fig. 1 (b). However, by considering the umbilical, sub-sea transformer and input filter combination, it can be readily shown that the system can be represented by the cascade filter arrangement of Fig. 13.

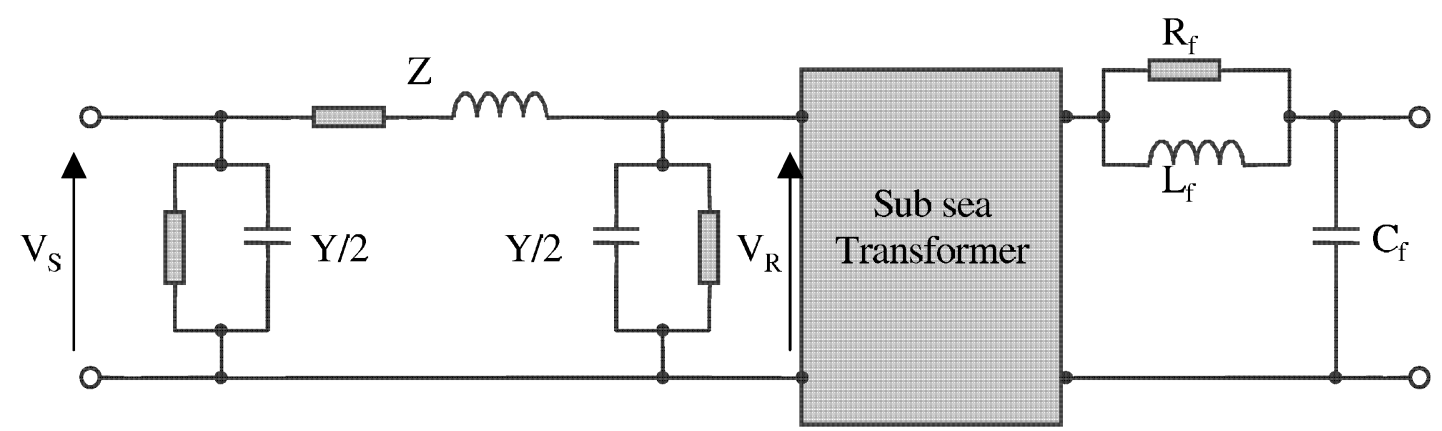

Fig. 13. Single phase of the umbilical model, transformer model and input filter 
As discussed previously, cascaded or multi-stage filters are often used to provide increased attenuation at high frequencies. Although a cascade filter requires more components when compared to singlestage counterparts, it will often provide a more compact arrangement. Moreover, due to the requirement for smaller/lower valued components, cost is often reduced [8].

From Fig. 13 it can be seen that the input filter can be considered to be a combined cascade arrangement of the umbilical impedance and the designated input filter, thereby reducing the size of reactive components. The resulting frequency response of the network, Fig. 14, shows increased attenuation at frequencies above $30 \mathrm{kHz}$. Although this will not significantly attenuate the switching frequency components, harmonics will be attenuated.

A reduction in the filter component size can be obtained by increasing the switching frequency of the converter, since the required corner frequency can be increased and the effects of the transmission line become more dominant. From the frequency response of the cascaded arrangement, Fig. 13, the necessity of the input filter is apparent. Current harmonics generated by the converter in the vicinity of the umbilical natural frequency would otherwise result in high voltage at the ROV terminals and large currents drawn from the surface generator.
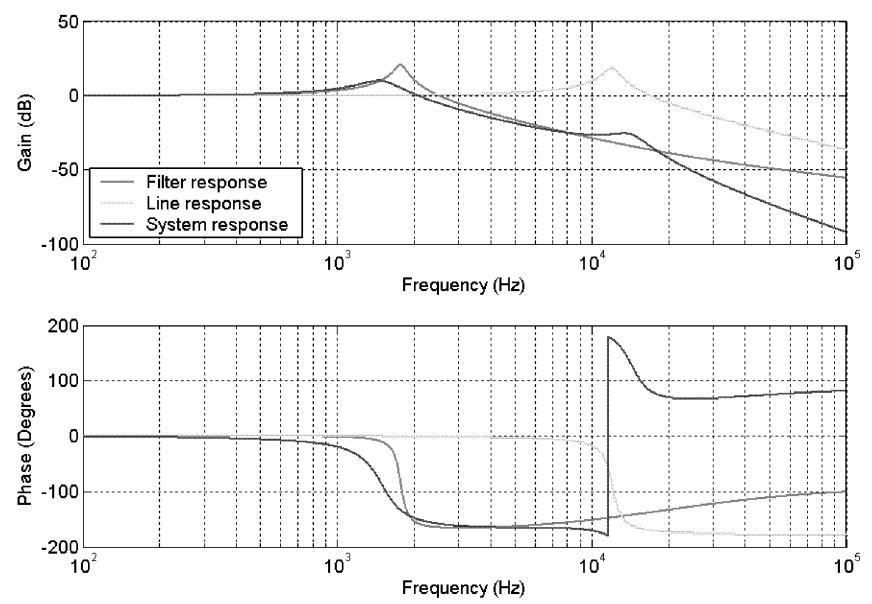

Fig. 14. Frequency response of the power transmission system

\section{Conclusions}

The selection of voltage and frequency for power transmission along a $3 \mathrm{~km}$ umbilical cable used to supply power to propulsion thrusters and other auxiliaries onboard a work-class ROV, have been discussed. It is shown that with increasing supply voltage, copper losses are reduced and the use of relatively high operating frequencies allows reductions in the mass of power system components, whilst having a negligible effect on the AC-resistance of the cable. The transmission voltage and frequency used to transmit power to the ROV is currently $3.3 \mathrm{kV}$, and $60 \mathrm{~Hz}$, respectively. With current hydraulic propulsion systems, there is little to be gained by varying these transmission parameters. Increasing the transmission voltage may offer minor benefits by reducing copper loss. However, this requires a redesign of the current induction-machine power pack and umbilical, and increasing the insulation. The benefits of increased transmission frequency would therefore only become apparent for all/more electric ROVs.

An appraisal of input filter configurations has been made. Whilst considering the frequency responses of the various filters, the LLC, LCC and the cascade arrangements show better attenuation at high frequency, although a second-order counterpart was shown to be comparable over the first decade beyond the corner frequency. Moreover, although the second order filter presented a marginal reduction in efficiency, compared to the LLC and LCC variants, the advantage of reduced component count, mass and volume ultimately outweighed this disadvantage. A design procedure for the filter has been presented, highlighting the importance of sizing the input filter components correctly to 
maintain the highest input displacement factor. It has been shown that an input displacement factor $>0.8$ is achievable for power levels $>300 \mathrm{~W}$, and $>0.9$ above $500 \mathrm{~W}$. Moreover, it has been shown that by appropriate selection of input filter structure, the impedance characteristics of the umbilical can be beneficially utilised to reduce the reactive component requirements.

\section{References}

[1] Abu.M.S Sharkh,. M.R Harris, R.M Crowder, "Comparative Studies of Electric and Hydraulic Drive System for Thrusters of Remotely Operated Vehicles". Oceanology International Conference 1994, Brighton, UK.

[2] P. Snary, C.M. Bingham, D.A Stone, N. Schofield, "Commercial Electrical Devices for Operation in High Pressure Deep-Sea Drive Systems”, PCIM 2001, pp275-280 June 19-21, Nurnberg, Germany.

[3] P. Snary, C.M. Bingham, D.A Stone, N. Schofield, "Drive System for Operation on Deep-Sea ROVs" ISBN : 90-75815-07-7, EPE 2003, Toulouse, France

[4] Power systems for RLCG line parameters

[5] J.A Ferreira, "Improved Analytical Modelling of Conductive Losses in Magnetic Components', IEEE Trans. on power electronics, Vol. 9, No. 1,pp. 127-131, January 1994.

[6] R.L.Stoll, "The Analysis of Eddy Currents", Oxford, Clarendon Press, 1974.

[7] P.W Wheeler; H. Zhang; D.A Grant, "A Theoretical and Practical Consideration of Optimised Input Filter Design for a Low Loss Matrix Converter" $5^{\text {th }}$ International Conference on Power Electronics and Variable Speed Drives, Conf. Publ. No.399. 363-7 IEE, London, UK. 1994.

[8] P. Wheeler, D. Grant "Optimised Input Filter Design and Low-Loss Switching Techniques for a Practical Matrix Converter" IEE Proceedings Electric Power Applications; 144(1): pp. 53-60 Jan. 1997

[9] C.L Neft, C.D Schauder, "Theory and Design of a 30-Hp Matrix Converter" Conference Record of the 1988 Industry Applications Society Annual Meeting IEEE, Cat.-No.88CH2565-0, pp. 934-9 vol.1, New York, NY, USA, 1988.

[10] J.C Clare, L. Empringham, P.W Wheeler, "The Effects of Sampling Delays and Nonideal Filtering on the Performance of Matrix Converter Modulation Algorithms", $8^{\text {th }}$ International Conference on Power Electronics and Variable Speed Drives, Conf-Publ.-No.475, pp. 29-34 IEE, London, UK. 2000.

[11] V. Vlatkovic, D. Borojevic, F.C.Lee, "Input Filter Design for Power Factor Correction Circuits", IEEE Transactions on Power Electronics, Vol.11, No.1,pp. 199-205, January 1996.

[12] V. Vlatkovic, D. Borojevic, F.C.Lee, "Input Filter Design for Power Factor Correction Circuits", IEEE Transactions on Power Electronics, Vol.11, No.1,pp. 199-205, January 1996. 